\title{
Variation in the ilium of central European water frogs Pelophylax (Amphibia, Ranidae) and its implications for species-level identification of fragmentary anuran fossils
}

\author{
Hugues-Alexandre Blain ${ }^{1,2^{*}}$, Iván Lózano-Fernández ${ }^{1,2}$ and Gottfried Böhme ${ }^{3}$
}

\begin{abstract}
Background: In the opinion of all field herpetologists and archaeozoologists, green frogs (living and sub-fossil specimens) are among the most difficult European amphibians to identify. Here, we examine the intra- and interspecific variation in both continuous and discrete iliac characters for refining the criteria for species-level identification among European green frogs Pelophylax ridibundus, Pelophylax lessonae and their associated klepton Pelophylax kl. P. esculentus (Amphibia, Ranidae).

Results: A total of 454 ilia of modern green frogs from the former German Democratic Republic have been studied: 168 for $P$. lessonae ( 86 of males and 82 of females), 118 for $P$. ridibundus ( 44 of males and 74 of females) and 168 for P. kl. P. esculentus (86 of males and 82 of females). The origin, sex, population structure and phenotype are known for each of the studied specimens. Eight variables have been taken (one angle and seven measurements), mainly on the distal part of the element in order to be able to apply them to fragmentary fossil ilia. Interspecific variations, sexual dimorphism and population structure have been investigated. Results suggest that the secure determination of a single fossil ilium at species level is quite impossible, but that at population level, it may be possible to distinguish between a 'pure' species or a 'pure' species plus its cohabiting hybrid form, as some minor differences have been evidenced in particular in the angle of the tuber superior in relation to iliac's main axis (character 2) and the width of the pars ascendens (character 8); two parameters significantly non size-dependent. No sexual dimorphism has been detected, except for $P$. lessonae.
\end{abstract}

Conclusions: We propose here a new biometrical method in order to differentiate between the fossil ilia of central European water frogs (genus Pelophylax) at population level.

Keywords: Ilium; Pelophylax; Osteology; Biometry; Klepton; Central Europe

\section{Background}

In the opinion of all field herpetologists, green frogs of genus Pelophylax ('palaearctic water frogs', formerly included in genus Rana until Frost et al. 2006) are among the most difficult European amphibians to identify (e.g. Lescure and de Massary 2012; Thirion and Evrard 2012). In parts of northern and central Europe, the green

\footnotetext{
* Correspondence: hablain@iphes.cat

'IPHES, Institut Català de Paleoecologia Humana i Evolució Social, c/ Marcel lí Domingo s/n (Edifici W3), Campus Sescelades, 43007 Tarragona, Spain ${ }^{2}$ Area de Prehistoria, Universitat Rovira i Virgili (URV), Avinguda de Catalunya 35, 43002 Tarragona, Spain

Full list of author information is available at the end of the article
}

frog complex consists of two species: the marsh frog (Pelophylax ridibundus) and the pool frog (Pelophylax lessonae), as well as the edible frog (Pelophylax kl. P. esculentus), a hybridogenetic form between these two species (Berger 1968; Tunner 1974). Genetic studies have also revealed the existence of various other species in the Mediterranean Basin (Beerli 1994; Beerli et al. 1994), for a total of seven species and two taxa with a hybrid origin in Europe (Sillero et al. 2014).

Throughout Europe, the situation is complicated by the existence of different systems of mixed populations. Due to the hybridogenetic system, $P$. kl. P. esculentus 
can live and reproduce in the presence of only one parental species. Their occurrences depend mainly on ecological predilections of the single parental species. $P$. lessonae is more demanding in this respect, needing sunlit waters with rich vegetation (Zahn 1997). P. ridibundus prefers larger water bodies and hibernates in the water, in contrast to P. lessonae. P. kl. P. esculentus is more flexible than its parental species and poses fewer demands on its habitat (Günther 1990; Plötner 2005). The most common system occurs in central and western Europe where the hybrid $P$. kl. $P$. esculentus lives in sympatry with the parental species $P$. lessonae (LE system). Massive differences in the genetic structures of different populations are possible in LE systems, with hybrids making up between 5 and $95 \%$ of the population (Berger 1990). Other common water frog systems consist of lineage of $P$. kl. P. esculentus breeds with $P$. ridibundus forming populations of the RE system, which also feature high structural genetic variability (Plötner 2005). There are also populations consisting of both parental species and the hybrid (RLE system); however, in these cases, it is unclear whether $P$. kl. P. esculentus stems from hybridogenetic reproduction or primary hybridization between the parental species (Günther 1991; Plötner 2005). Finally, there is also all-hybrid populations (EE system) that have become reproductively independent of the parental forms owing to polyploidization, i.e. via triploid individuals (Günther 1975; Uzzell and Berger 1975; Ebendal and Uzzell 1982; Regnier and Neveu 1986; Pruvost et al. 2013) and which mainly occur in the northern region of the distribution range (Ebendal 1979; Eikhorst 1987).

While $P$. lessonae and $P$. ridibundus are significantly morphologically different, hybrids show a more or less intermediate appearance between those of their putative parents. The differentiation between these morphological types lies in several characteristics such as the size, the shape of the nose, the length of the hind legs, the extent of the webbing of the toes, the metatarsal profile tubers, the layout and size of dark spots on the sides and back, the form of the veins and the background colour of the posterior thigh, the shape and arrangement of vomerine denticles, the colour of vocal sacs and nuptial pads (on adult males), or biometric ratios (e.g. leg length, body length, tibia length, length of the first toe, height and length of the metatarsal tubercle and distance between the eye and the eardrum) (Berger 1966; Gubányi and Korsós 1992; Mayer et al. 2013). However, for living populations, the genetic approach is the only completely reliable methodology (Lescure and de Massary 2012).

According to the genetic data, the natural distribution of green frogs and hybrids is due to the differentiation of genetically closely related species that, from the Pleistocene to the Holocene, became isolated separately in refugia during glacial periods and were put into contact again during warmer periods. Secondary contact of diverged genetic entities can lead to hybridization when it happens before effective premating barriers have developed (Pruvost et al. 2013). After the last Pleistocene glaciation, the warming period that followed during the Holocene probably allowed green frogs to extend their range to the north of Europe, naturally creating hybrid zones (Thirion and Evrard 2012). However, the glacial/interglacial dynamics allow this type of hybridization throughout the Pleistocene, although the lack of reliable criteria for such determination has hardly helped provide paleontological data to support these different theories.

In the fossil and sub-fossil record, isolated anuran ilia are among the most commonly recovered anuran bones from fossil microvertebrate sites thanks to their relatively robust build and distinctive structure. They are widely considered to be the single best element upon which to base fossil identifications when isolated bones are all that is available. According to Sanchiz (1998), approximately $40 \%$ of extinct frog species' denominations are based on disarticulated material with the ilium designated as the holotype. Consequently, the proposal of this study is to examine the intra- and interspecific variation in both continuous and discrete iliac characters for refining the criteria for species-level identification among European green frogs $P$. ridibundus, $P$. lessonae and their associated klepton P. kl. P. esculentus (Amphibia, Ranidae).

\section{Methods}

The studied sample includes complete dry disarticulated skeletons from East Germany prepared in 1976 by one of us (see Böhme 1977 and Böhme and Günther 1979 for more details). This material is stored in the collections of the Museum für Naturkunde (Berlin, Germany). From this sample, we selected the isolated ilia (both right and left) of some 227 specimens of green frogs: 59 P. ridibundus (22 males and 37 females), 84 P. kl. P. esculentus (43 males, 41 females) and $84 \mathrm{P}$. lessonae (43 males, 41 females). Measurements have been taken through camera lucidascaled drawings. Osteological nomenclature mainly follows Sanchiz (1998). For the nomenclatural treatment of klepton, we follow the proposals of Dubois and Günther (1982) and Dubois (1991).

We selected as many metric characters as possible for ilium, taking into account that they must be reproducible on fragmentary fossils (Figure 1; Table 1). Measurements have been done as follows: character 1, projected length of ilium on the line that goes from the upper part of the intersection between the acetabulum and the posterior margin and that is tangential to the highest point of the iliac's lower margin (Sanchiz et al. 1993; measurement 3 or IL); character 2, angle between the tuber superior and the iliac's main axis (Sanchiz et al. 1993; measurement 2 called ANG); character 3 , dorsal crest height (measurement 1 or $\mathrm{CDH}$ in Sanchiz et al. 1993 and 


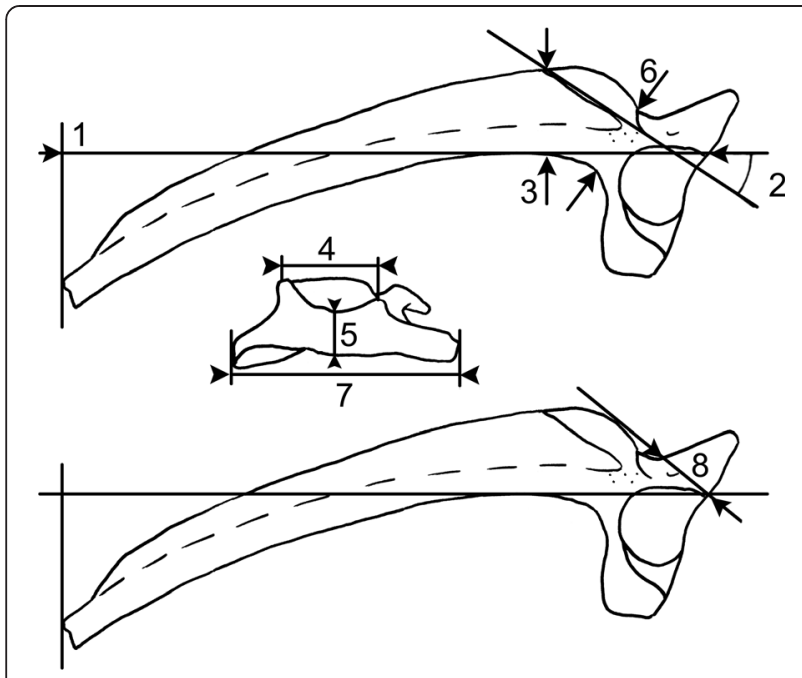

Figure 1 Measurements used on green frog's ilium. 1, length of ilium; 2, angle between tuber superior orientation and main iliac axis; 3 , dorsal crest height; 4 , acetabular diameter; 5 , corpus thickness at the centre of the acetabulum; 6, 'iliac neck' (=smallest thickness of the crest on the corpus); 7 , maximum width of the junctura ilioischiadica; 8 , width of the pars ascendens.

measurement d in Böhme and Günther 1979); character 4, acetabular diameter (measurement a in Esteban and Sanchiz 1985, measurement b in Böhme and Günther 1979 and measurement d in Gleed-Owen 1998, 2000); character 5 , corpus thickness at the centre of the acetabulum (measurement a in Böhme and Günther 1979 and measurement $\mathrm{t}$ in Gleed-Owen 1998, 2000); character 6, 'iliac neck' or smallest thickness of the crest on the corpus (measurement e in Böhme and Günther 1979); character 7 , maximum width of the junctura ilioischiadica; and character 8 , width of the pars ascendens on the imaginary line that is tangential to the tuber superior's dorsal margin and that crosses the point at the intersection between the upper part of the acetabulum and the posterior edge of the ilia.

The standard non-parametric Mann-Whitney $U$ test has been used to compare the measurements between species, population structure and sex and the Kendall's tau $(\tau)$ coefficient, and Spearman's rank correlation coefficient has been used to measure the association between iliac measurements and size on a personal computer with the Paleontological Statistics (PAST) programme (Hammer et al. 2001). These two tests are non-parametric hypotheses which establish whether two variables may be regarded as statistically dependent. Using the PAST programme, we can also obtain the probability $(p)$ that the two variables are not correlated (uncorr).

To compare measurements, we used projection and boxplot sketches (Hammer et al. 2001). These boxplots display summary statistics for the distribution and plot the median, the 25 th percentile, the 75 th percentile and
Table 1 Statistics of iliac measurements of Pelophylax ridibundus, Pelophylax lessonae and their hybrid klepton Pelophylax kl. P. esculentus

\begin{tabular}{lcccccccc}
\hline Characters & $\mathbf{1}$ & $\mathbf{2}$ & $\mathbf{3}$ & $\mathbf{4}$ & $\mathbf{5}$ & $\mathbf{6}$ & $\mathbf{7}$ & $\mathbf{8}$ \\
\hline P. ridibundus & (male + female) & & & & & & \\
N & 115 & 116 & 116 & 113 & 113 & 116 & 113 & 116 \\
Mean & 27.60 & 36.00 & 3.65 & 4.20 & 1.70 & 3.40 & 10.00 & 2.50 \\
SD & 4.72 & 3.46 & 0.61 & 0.76 & 0.38 & 0.52 & 1.77 & 0.43 \\
Min & 17.60 & 28.00 & 2.40 & 2.80 & 1.00 & 2.20 & 6.40 & 1.60 \\
Max & 36.00 & 45.00 & 5.00 & 5.60 & 2.40 & 4.50 & 13.00 & 3.40 \\
P. kl. P. esculentus (male + female) & & & & & & \\
N & 165 & 168 & 168 & 165 & 165 & 168 & 165 & 168 \\
Mean & 21.20 & 43.00 & 3.40 & 3.40 & 1.40 & 2.80 & 7.80 & 1.80 \\
SD & 2.91 & 4.05 & 0.46 & 0.48 & 0.24 & 0.37 & 1.10 & 0.32 \\
Min & 10.60 & 28.00 & 1.80 & 1.50 & 0.60 & 1.60 & 3.40 & 1.00 \\
Max & 28.10 & 53.00 & 4.40 & 4.40 & 2.00 & 3.60 & 10.80 & 3.00 \\
P. lessonae (male +female) & & & & & & \\
N & 167 & 168 & 168 & 161 & 161 & 168 & 161 & 168 \\
Mean & 18.40 & 46.00 & 3.00 & 3.00 & 1.20 & 2.40 & 6.60 & 1.60 \\
SD & 2.28 & 4.32 & 0.40 & 0.33 & 0.20 & 0.27 & 0.79 & 0.21 \\
Min & 11.00 & 35.00 & 2.00 & 1.80 & 0.70 & 1.70 & 3.60 & 0.80 \\
Max & 24.20 & 56.00 & 4.40 & 3.80 & 1.80 & 3.20 & 8.40 & 2.00
\end{tabular}

P. kl. P. esculentus (RE)

N

M

$\mathrm{M}$

SD

Min

$$
36
$$$$
38
$$

38

$\begin{array}{llllll}38 & 38 & 38 & 38 & 38 & 38 \\ 3.40 & 3.40 & 1.40 & 2.85 & 7.85 & 2.00 \\ 0.43 & 0.42 & 0.20 & 0.34 & 1.00 & 0.31 \\ 2.80 & 2.80 & 1.10 & 2.40 & 6.40 & 1.60 \\ 4.20 & 4.20 & 2.00 & 3.60 & 10.80 & 3.00\end{array}$

P. kl. P. esculentus (LE)

$\begin{array}{lllllllll}N & 123 & 124 & 124 & 121 & 121 & 124 & 121 & 124 \\ \text { Mean } & 21.20 & 44.00 & 3.30 & 3.40 & 1.40 & 2.80 & 7.60 & 1.80 \\ \text { SD } & 3.16 & 4.37 & 0.47 & 0.50 & 0.24 & 0.37 & 1.12 & 0.31 \\ \text { Min } & 10.60 & 28.00 & 1.80 & 1.50 & 0.60 & 1.60 & 3.40 & 1.00 \\ \text { Max } & 28.10 & 53.00 & 4.40 & 4.40 & 2.00 & 3.60 & 9.60 & 2.60\end{array}$

P. ridibundus (male)

N N 42

Mean 42
28.40 $42-42$

\section{SD}

4.28

Min

19.20

Max

33.20

P. ridibundus (female)

N

Mean

SD

Min

$\operatorname{Max}$

\section{3}

26.20

4.98

17.60

36.00
$41.00 \quad 3.40$

$2.12 \quad 0.43$

$37.00 \quad 2.80$

$\begin{array}{lllllll}46.00 & 4.20 & 4.20 & 2.00 & 3.60 & 10.80 & 3.00\end{array}$ 


\section{Table 1 Statistics of iliac measurements of Pelophylax ridibundus, Pelophylax lessonae and their hybrid klepton Pelophylax kl. P. esculentus (Continued)}

\begin{tabular}{|c|c|c|c|c|c|c|c|c|}
\hline \multicolumn{9}{|c|}{ P. kl. P. esculentus (male) } \\
\hline$N$ & 83 & 86 & 86 & 85 & 85 & 86 & 85 & 86 \\
\hline Mean & 21.00 & 43.00 & 3.40 & 3.40 & 1.40 & 2.80 & 7.80 & 1.80 \\
\hline SD & 2.60 & 3.59 & 0.47 & 0.47 & 0.23 & 0.36 & 1.09 & 0.31 \\
\hline Min & 10.60 & 33.00 & 1.80 & 1.50 & 0.60 & 1.60 & 3.40 & 1.00 \\
\hline Max & 26.60 & 53.00 & 4.20 & 4.20 & 2.00 & 3.60 & 10.80 & 3.00 \\
\hline \multicolumn{9}{|c|}{ P. kl. P. esculentus (female) } \\
\hline$N$ & 82 & 82 & 82 & 80 & 80 & 82 & 80 & 82 \\
\hline Mean & 21.50 & 42.00 & 3.30 & 3.40 & 1.40 & 2.80 & 7.80 & 1.90 \\
\hline SD & 3.17 & 4.36 & 0.46 & 0.49 & 0.25 & 0.38 & 1.11 & 0.32 \\
\hline Min & 12.60 & 28.00 & 2.20 & 2.00 & 0.80 & 1.70 & 4.40 & 1.20 \\
\hline Max & 28.10 & 53.00 & 4.40 & 4.40 & 2.00 & 3.60 & 9.60 & 2.60 \\
\hline \multicolumn{9}{|c|}{ P. lessonae (male) } \\
\hline$N$ & 86 & 86 & 86 & 81 & 81 & 86 & 81 & 86 \\
\hline Mean & 18.00 & 45.00 & 3.00 & 3.00 & 1.20 & 2.40 & 6.40 & 1.60 \\
\hline SD & 2.31 & 4.22 & 0.42 & 0.35 & 0.20 & 0.30 & 0.85 & 0.22 \\
\hline Min & 11.00 & 37.00 & 2.00 & 1.80 & 0.70 & 1.70 & 3.60 & 0.80 \\
\hline Max & 24.00 & 55.00 & 3.80 & 3.60 & 1.60 & 3.00 & 8.20 & 1.90 \\
\hline \multicolumn{9}{|c|}{ P. lessonae (female) } \\
\hline$N$ & 81 & 82 & 82 & 80 & 80 & 82 & 80 & 82 \\
\hline Mean & 19.60 & 46.50 & 3.00 & 3.00 & 1.20 & 2.40 & 6.70 & 1.60 \\
\hline SD & 1.86 & 4.30 & 0.36 & 0.28 & 0.19 & 0.23 & 0.67 & 0.18 \\
\hline Min & 16.40 & 35.00 & 2.60 & 2.40 & 0.90 & 2.10 & 5.90 & 1.20 \\
\hline Max & 24.20 & 56.00 & 4.40 & 3.80 & 1.80 & 3.20 & 8.40 & 2.00 \\
\hline
\end{tabular}

Abbreviations: $N$ number of elements, SD standard deviation, Min minimum, Max maximum, $R E$ ridibundus-esculentus population structure, $L E$ lessonae-esculentus population structure. For measurement explanations, see Figure 1.

values more than 1.5 box lengths from 75 th percentile (outliers).

\section{Results}

Interspecific variations

Mean, standard deviation and range have been computed for all variables (Table 1). According to Figure 2A,B, none of the studied measurements shows a complete separation (when taking into account minimum and maximum values) for none of the studied parental species and klepton. However, when taking into account the mean value and the standard deviation (95\% of the values), some distinctions are visible. The results of the Mann-Whitney $U$ test (Table 2) suggest that the difference between species and klepton are highly significant for all characters but for character 3 between $P$. ridibundus and $P$. kl. $P$. esculentus that is only significant. According to the projection of character's values (Figure 2A,B), those that present the highest differences between species are characters
1, 2, 7 and 8. Ilium length (character 1) is assumed by Sanchiz et al. (1993) as a good estimator of individual absolute size. Thus, in the studied sample, it appears that ilia from $P$. ridibundus $(27.6 \pm 4.7 \mathrm{~mm})$ are larger than those of $P$. kl. P. esculentus $(21.2 \pm 2.9$ $\mathrm{mm})$ and than those of $P$. lessonae $(18.4 \pm 2.3 \mathrm{~mm})$. Such a difference in size has already been reported by field herpetologists (e.g. Günther 1990; Plötner 2005). The angle between the orientation of the tuber superior and main iliac axis (character 2) shows also some differences between $P$. ridibundus $\left(36.0 \pm 3.5^{\circ}\right)$ and $P$. kl. $P$. esculentus $+P$. lessonae (respectively $43.0 \pm 4.0^{\circ}$ and $46.0 \pm 4.3^{\circ}$ ). For all the other characters, the ordination of values seems to follow that of the size ( $P$. ridibundus $>P$. kl. $P$. esculentus $>P$. lessonae) like for character 7 (maximum width of the junctura ilioischiadica) larger in $P$. ridibundus $(10.0 \pm 1.8 \mathrm{~mm})$ than in $P$. kl. $P$. esculentus $(7.8 \pm 1.1 \mathrm{~mm})$ and $P$. lessonae $(6.6 \pm 0.8 \mathrm{~mm})$, and character 8 (width of the pars ascendens) where $P$. ridibundus $(2.5 \pm 0.4 \mathrm{~mm})$ is larger than $P$. kl. $P$. esculentus $(1.8 \pm 0.3$ $\mathrm{mm})$ and $P$. lessonae $(1.6 \pm 0.2 \mathrm{~mm})$.

In order to remove from the analysis size-linked differences, we perform a statistical analysis using Spearman's rank and Kendall's Tau tests to search characters that are not size-dependent. As said above, character 1 has been taken as reference for the size of the whole individual. Among characters, only characters 2 and 8 are demonstrated to be size-independent (Table 3). Among other characters, character 7 is the one that shows the highest dependence with size with a Spearman's rank value of 0.97 followed by character 4 with 0.94 and character 6 with 0.93 .

\section{Variation according to population structure}

Differences in iliac morphology in relation with the population structure (as defined in the introduction) of the hybrid klepton $P$. kl. P. esculentus have been investigated (Figure 2C). Characters for the LE system and RE system have been studied separately. The few triploid individuals have been removed from the analysis. The results of the Mann-Whitney $U$ test (Table 2) suggest that the difference between RE and LE systems are highly significant for characters 2 and 8 and significant for character 5 . There is no difference for character 1 (estimate of absolute size) between the two systems with respectively $21.20 \pm 2.09 \mathrm{~mm}$ for $\mathrm{RE}$ and $21.20 \pm 3.16 \mathrm{~mm}$ for LE systems. Character 2 (tuber superior's orientation) is the one that seems to show the largest difference between the two systems (lowest value for two-tailed probability $p$ ), with $41.00 \pm 2.12^{\circ}$ for RE and $44.00 \pm 4.37^{\circ}$ for LE. Character 8 (width of the pars ascendens) although highly significant shows some tiny difference between RE $(2.00 \pm 0.31 \mathrm{~mm})$ and $\operatorname{LE}(1.80 \pm$ $0.31 \mathrm{~mm}$ ) systems, as well as character 5 (acetabulum thickness) that although significant shows the same mean for $R E(1.40 \pm 0.20 \mathrm{~mm})$ than for $\operatorname{LE}(1.40 \pm 0.24 \mathrm{~mm})$. 

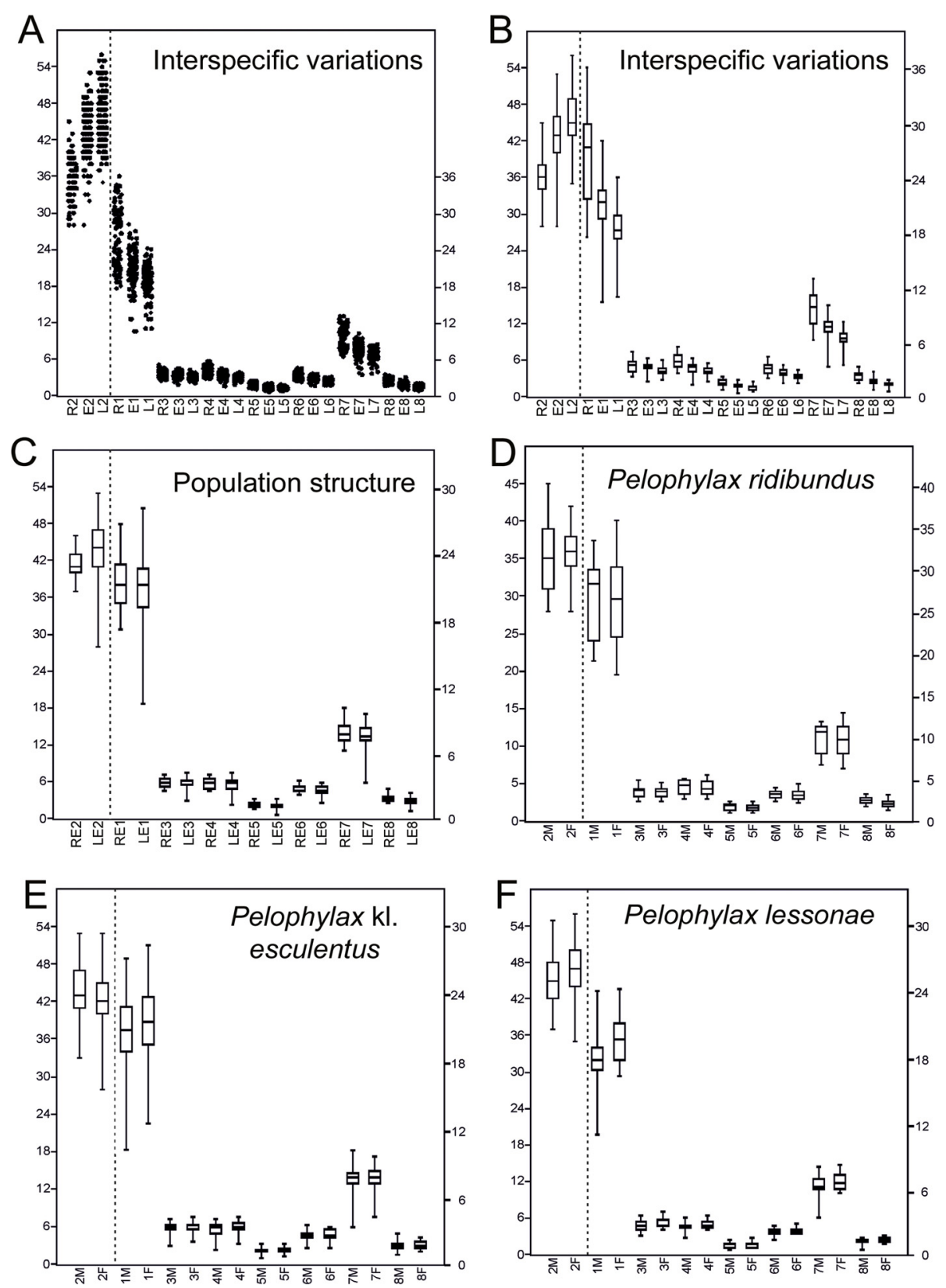

Figure 2 Projection, differences in iliac morphology and sexual dimorphism. Projection and boxplot of all characters (A), (B) and according to their population structure (C) and sexual dimorphism (D), (E), (F). Numbers in abscissa correspond to character's number. Abbreviations: $E, P$. kl. esculentus; L, P. lessonae; R, P. ridibundus; LE, P. kl. esculentus within the lessonae-esculentus system; RE, P. kl. esculentus within the ridibundus-esculentus system; M, male; F, female. Measurements (right of the dotted line) and angle (on the left) are respectively in millimetres and in sexigesimal degree.

\section{Sexual dimorphism}

Finally, sexual dimorphism has also been investigated (Figure 2D,E,F). According to osteological observations, all the specimens from our samples correspond to adult individuals (ossification of the pubis, etc.). The sex of the individuals was already annotated on the specimens and has been checked using the humerus (presence/ absence of crests). For character 1 (ilium length as estimate of absolute size), quite no significant differences have been found between male and female of $P$. ridibundus with the ilia of males $(28.40 \pm 4.28 \mathrm{~mm})$ slightly larger than the ilia of females $(26.20 \pm 4.98 \mathrm{~mm})$, as well as in $P$. kl. P. esculentus (male $=21.00 \pm 2.60 \mathrm{~mm}$; female $=21.50 \pm$ $3.17 \mathrm{~mm}$ ). Nevertheless, the difference between males and females in $P$. lessonae is highly significant (Table 2) with the ilia of males $(18.00 \pm 2.31 \mathrm{~mm})$ slightly smaller than the ilia of females $(19.60 \pm 1.86 \mathrm{~mm})$. There is an accepted hypothesis that explains the status and direction of sexual 
Table 2 Results of Mann-Whitney $\boldsymbol{U}$ test comparing the differences for each character

\begin{tabular}{|c|c|c|c|c|c|c|c|c|}
\hline & 1 & 2 & 3 & 4 & 5 & 6 & 7 & 8 \\
\hline \multicolumn{9}{|l|}{ Interspecific variations } \\
\hline$P$. ridibundus $\times P$. kl. $P$. esculentus & $\mathrm{H}$ & $\mathrm{H}$ & $S$ & $\mathrm{H}$ & $\mathrm{H}$ & $\mathrm{H}$ & $\mathrm{H}$ & $\mathrm{H}$ \\
\hline$P$. ridibundus $\times P$. lessonae & $\mathrm{H}$ & $\mathrm{H}$ & $\mathrm{H}$ & $\mathrm{H}$ & $\mathrm{H}$ & $\mathrm{H}$ & $\mathrm{H}$ & $\mathrm{H}$ \\
\hline$P$. lessonae $\times P$. kl. P. esculentus & $\mathrm{H}$ & $\mathrm{H}$ & $\mathrm{H}$ & $\mathrm{H}$ & $\mathrm{H}$ & $\mathrm{H}$ & $\mathrm{H}$ & $\mathrm{H}$ \\
\hline \multicolumn{9}{|l|}{ Population structure } \\
\hline$R E \times L E$ & $\mathrm{~N}$ & $H$ & $\mathrm{~N}$ & $N$ & $S$ & $N$ & $\mathrm{~N}$ & $\mathrm{H}$ \\
\hline \multicolumn{9}{|l|}{ Sexual dimorphism } \\
\hline P. ridibundus & $N$ & $\mathrm{~N}$ & $\mathrm{~N}$ & $\mathrm{~N}$ & $\mathrm{~N}$ & $\mathrm{~N}$ & $\mathrm{~N}$ & $\mathrm{~N}$ \\
\hline P. kl. P. esculentus & $\mathrm{N}$ & $S$ & $\mathrm{~N}$ & $\mathrm{~N}$ & $\mathrm{~N}$ & $\mathrm{~N}$ & $\mathrm{~N}$ & $\mathrm{~N}$ \\
\hline P. lessonae & $H$ & $\mathrm{~S}$ & $\mathrm{H}$ & $S$ & $\mathrm{~S}$ & $\mathrm{H}$ & $S$ & $\mathrm{H}$ \\
\hline
\end{tabular}

$\mathrm{N}=$ two-tailed probability $p>0.05 ; \mathrm{S}=0.05>p>0.01 ; \mathrm{H}=p<0.01$.

size dimorphism in anurans, where males are usually smaller than females as a result of sexual selection (Monnet and Cherry 2002). In 90\% of the anuran species, the females are larger than males (Shine 1979). Water frogs do not make exception to the rule (Günther 1990; Plötner 2005). These results may indicate that there may have had biases (human size selection) during the capture of the water frogs, especially for $P$. ridibundus and P. kl. P. esculentus.

The results of the Mann-Whitney $U$ test (Table 2) suggest that the difference between males and females is also highly significant in P. lessonae for characters 3, 6 and 8 and significant for the other ones (Table 2). For other taxa, differences between male and female are not significant for all the studied characters, unless character 2 in P. kl. P. esculentus.

Biometrical differentiation between European water frogs Characters 2 and 8 have been demonstrated to be the best characters for separation between the three studied water frog taxa, independently of the size. When considering the projection of characters 2 and 8 (Figure 3A,B), $P$. lessonae clearly separates from $P$. ridibundus. $P$. kl. $P$. esculentus has been separated according to its population structure (systems RE and LE). RE and LE largely overlaps between each others and part of the distribution of the parental species. RE mainly overlaps the distribution of $P$. ridibundus, whereas LE overlaps quite all the distribution of $P$. lessonae. In consequence, the specific attribution of a single ilium appears to be highly hypothetic, unless in some case for $P$. ridibundus that shows the largest difference with other species and systems. Nevertheless, with a minimum number of ilia, the distribution of their measurements (characters 2 and 8 ) within the variability of each species and system would permit to differentiate between pure species and possibly mixed populations. Only the pure populations of $P$. lessonae seem to be impossible to securely differentiate from the LE system.

\section{Discussion}

According to Sanchiz's review (1998) of the Salentia fossil record, 'Rana esculenta' has rarely been detected as a fossil, and in older literature, references to ' $R$. esculenta' should be now considered Pelophylax (ridibundus) sp. The only reliable fossil mention according to Sanchiz (1998) has been made for the Late Pleistocene and Holocene of Pisede (Germany; Böhme 1983a, b), whereas according to Martín and Sanchiz (2014) database, P. lessonae is mentioned since the Late Pliocene of Korotoyak-Belogor'e (Voronezh, Russia; Ratnikov 2001a) and P. ridibundus probably since the Early Pliocene (MN14) of Nurnus (Kotayk, Armenia; Vasilyan 2009).

Since Ecker (1889) examined the osteology of $P$. kl. P. esculentus in detail (=group lessonae + esculentus + ridibundus), very little literature has dealt with the osteology of individual species on a comparative basis. Böhme (1977) summed up the history of such work and highlighted the problems of uncertainty over identification, particularly of the green frogs. Böhme (1977) studied at least 20 specimens of each green frog species and, yet, concluded that they could not be separated using the ilium. The range of variation found within them is likely to be gradational, due to their shared genetic character. Some morphological traits are distinctive in the parent species, but these appear to be blurred in the different forms of $P$. kl. P. esculentus. Böhme and Günther (1979) carried out a more extensive study on a modern and sub-fossil material, using biometric methods, which permitted some specific diagnosis. Whereas frontoparietal was found to show significant differences between $P$. lessonae, $P$. ridibundus and $P$. kl. P. esculentus, ilium was shown to have a few characteristics permitting to separate $P$.

Table 3 Statistical analyses of the correlation between measurements and iliac length (character 1)

\begin{tabular}{llllllll}
\hline & $\mathbf{2}$ & $\mathbf{3}$ & $\mathbf{4}$ & $\mathbf{5}$ & $\mathbf{6}$ & $\mathbf{7}$ & $\mathbf{8}$ \\
\hline Kendall's Tau & -0.3298 & 0.702 & 0.844 & 0.7813 & 0.8225 & 0.8794 & 0.2528 \\
$p$ (uncorr) & $2.08 \mathrm{E}-25$ & $5.72 \mathrm{E}-109$ & $1.93 \mathrm{E}-152$ & $6.69 \mathrm{E}-131$ & $7.26 \mathrm{E}-145$ & $2.51 \mathrm{E}-165$ & $3.09 \mathrm{E}-16$ \\
Spearman's rank & -0.4738 & 0.8527 & 0.9464 & 0.9058 & 0.9388 & 0.9726 & 0.3179 \\
$p$ (uncorr) & $2.14 \mathrm{E}-26$ & $1.45 \mathrm{E}-127$ & $1.10 \mathrm{E}-214$ & $1.41 \mathrm{E}-163$ & $1.83 \mathrm{E}-202$ & $1.25 \mathrm{E}-276$ & $1.13 \mathrm{E}-11$ \\
\hline
\end{tabular}

Abbreviations: $p$ (uncorr) probability that the variables are uncorrelated. Uncorrelated variables are in italics. 

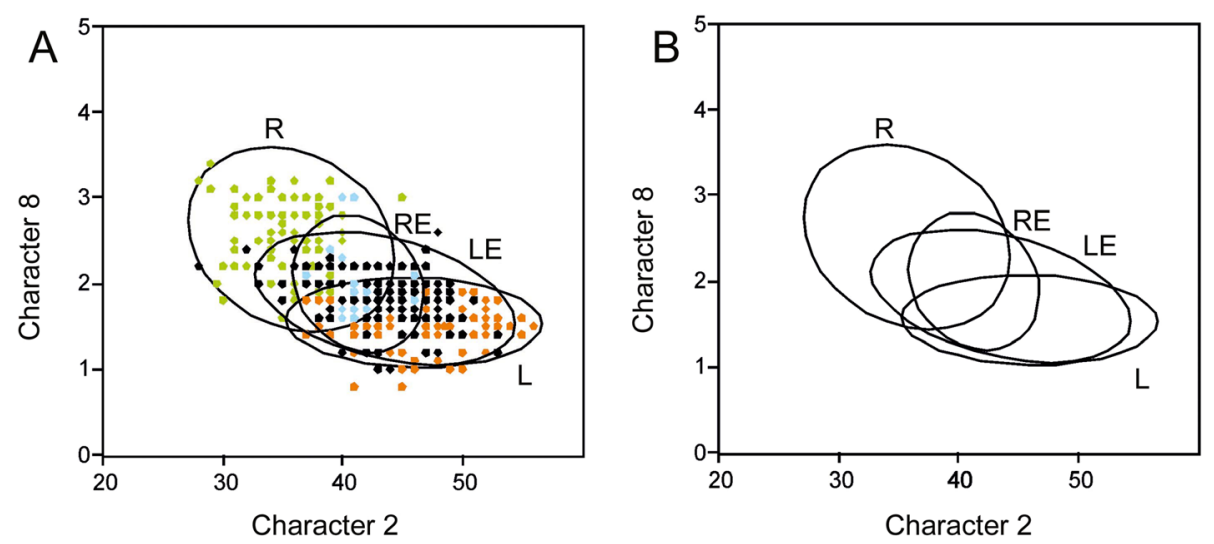

Figure 3 Biometrical separation between central European water frogs. Projections of characters 2 and 8 (A), (B).Abbreviations: L, P. lessonae; R, P. ridibundus; LE, P. kl. P. esculentus within the lessonae-esculentus system; RE, P. kl. P. esculentus within the ridibundus-esculentus system. Measurements (in ordinate) and angle (in abscissa) are respectively in millimetres and in sexigesimal degree.

lessonae from $P$. ridibundus $+P$. kl. P. esculentus. The morphological differences mainly lie in the development of the tuber superior, in particular in P. lessonae where this structure is very strong, laterally prominent and relatively steep, developing over the anterior border of the acetabulum (Böhme and Günther 1979). The same conclusions have been raised by Gleed-Owen $(1998,2000)$ from the study of 20 individuals each of $P$. ridibundus and $P$. kl. $P$. esculentus and 3 individuals of $P$. lessonae all from Britain, but not from a biometrical way. According to these differences, Gleed-Owen (2000) proposed that one fossil fragmentary ilium may cautiously be referred to the pool frog $P$. lessonae in a Middle Saxon (Chopdike Drove, c. 600 to $950 \mathrm{AD}$ ) site in Lincolnshire and so that $P$. lessonae was native from Britain. Although such an attribution has been posteriorly contested (e.g. Langton and Burton 2005), further phylogenetic studies demonstrate that $P$. lessonae was effectively native from Great Britain (Snell et al. 2005). Finally, Ratnikov (2001b) also noticed some differences in the morphology of the tuber superior between $P$. ridibundus and $P$. lessonae using Russian individuals, but does not include $P$. kl. $P$. esculentus in his study.

From a biometrical point of view, Böhme and Günther (1979) showed that the angle between the main iliac axis and the posterior border of the ilium was distinctive, measuring less than $55^{\circ}\left(\mathrm{min} / \mathrm{max}=43^{\circ}\right.$ to $\left.55^{\circ}\right)$ in $P$. kl. $P$. esculentus and $P$. ridibundus, while in $P$. lessonae, it is mainly over $55^{\circ}\left(\min / \max =52^{\circ}\right.$ to $\left.58^{\circ}\right)$. Unfortunately, the complete bone is needed for the measurement of this angle as proposed by Böhme and Günther (1979) and, consequently, not applicable on fragmentary fossils and so has been disregarded in our study. Our character 2 has been taken from Sanchiz et al. (1993) that studied five individuals of each $P$. ridibundus, $P$. kl. $P$. esculentus and $P$. lessonae from the collections of the Charles
University in Prague (Czech Republic) and of the Museo Nacional de Ciencias Naturales de Madrid (Spain). According to Sanchiz et al. (1993) biometric analyses, the angle between the tuber superior orientation and the main iliac axis (ANG = our character 2) was demonstrated to be independent of the size of the element and, although the sample was reduced, permitted to distinguish $P$. lessonae $\left(44.40 \pm 7.83^{\circ} ; \mathrm{min} / \mathrm{max}=32.00^{\circ}\right.$ to $\left.52.00^{\circ}\right)$ from $P$. ridibundus $\left(37.30 \pm 4.49^{\circ} ; \min / \max =34.00^{\circ}\right.$ to $\left.45.00^{\circ}\right)$ and P. kl. P. esculentus $\left(37.80 \pm 6.94^{\circ} ; \mathrm{min} / \mathrm{max}=32.00^{\circ}\right.$ to $\left.48.00^{\circ}\right)$. The results obtained from our larger sample (84 P. lessonae, 59 P. ridibundus and 84 P. kl. P. esculentus) are quite similar to the values obtained by Sanchiz et al. (1993) for $P$. ridibundus $\left(36.0 \pm 3.5^{\circ}\right)$ and $P$. lessonae $\left(46.0 \pm 4.3^{\circ}\right)$ but strongly differs for $P$. kl. P. esculentus $\left(43.0 \pm 4.0^{\circ}\right)$. Even the separation according to the population structure does not explain such difference with $41.00 \pm 2.12^{\circ}$ for RE system and $44.00 \pm 4.37^{\circ}$ for LE system. Finally, we note that minimum $\left(28.00^{\circ}\right)$ and maximum $\left(53.00^{\circ}\right)$ values for character 2 in $P$. kl. $P$. esculentus are comprised within the minima maxima given by Sanchiz et al. (1993). Such differences may stress that in future studies, a minimum number of individuals (at least higher than five) will be required in order to separate the fragmentary fossil ilia of central European water frogs at species level.

\section{Conclusions}

A total of 454 ilia of modern central European water frogs have been studied from a biometrical point of view in order to propose criterions that will permit the differentiation between the different species and klepton $P$. lessonae, $P$. ridibundus and $P$. kl. P. esculentus from fossil fragmentary ilia recovered in paleontological and archaeological localities. Eight variables have been taken, mainly located on the distal part of the element in order to be able to apply them 
to fragmentary fossil ilia. Among our measurements, two parameters (characters 2 and 8) have been demonstrated to be significantly size-independent. Character 2 (tuber superior's orientation $=$ ANG in Sanchiz et al. 1993) and character 8 (width of the pars ascendens) are also the ones that show the largest difference between species and between the two systems of $P$. kl. P. esculentus. Character 2 is smaller for $P$. ridibundus $\left(36.0 \pm 3.5^{\circ}\right)$ than for $P$. kl. $P$. esculentus $+P$. lessonae (respectively $43.0 \pm$ $4.0^{\circ}$ and $\left.46.0 \pm 4.3^{\circ}\right)$. Character 8 is larger for $P$. ridibundus $(2.5 \pm 0.4 \mathrm{~mm})$ than for $P$. kl. P. esculentus $(1.8 \pm 0.3 \mathrm{~mm})$ and $P$. lessonae $(1.6 \pm 0.2 \mathrm{~mm})$. As sexual dimorphism is taken into account, no major differences on the ilium have been put in evidence even if $P$. lessonae shows some significant differences in the measurements between males and females. All these results suggest that the secure determination of a single fossil ilium at species level is quite impossible, but that at population level, it must be possible to distinguish between a 'pure' species or a 'pure' species plus its cohabiting hybrid form (i.e. population structure LE or RE) according to the dispersion of the values of characters 2 and 8.

\section{Competing interests}

The authors declare that they have no competing interests.

\section{Authors' contributions}

GB prepared the osteological collections. HAB and ILF performed the statistical analyses and interpreted the data. HAB conceived the study, performed the data collection and wrote the manuscript. All authors read and approved the final manuscript.

\section{Acknowledgements}

This study is the result from the SYNTHESYS grant DE-TAF-3244 'Osteology of European green frogs (Pelophylax, Amphibia)' at the Museum für Naturkunde (Berlin, Germany). HAB wants to acknowledge Jean-Claude Rage (MNHN, Paris) and Zbyněk Roček (Laboratory of Paleobiology, Geological Institute, Prague) for their unconditional support and encouragements to this project. We are grateful to the DE-TAF team in Berlin especially to the administrative staff Manja Voss and to Florian Witzmann for their help during the realization of this work. Authors also thank Professor Sin-Che Lee managing editor, Massimo Delfino (University of Torino, Italy) and an anonymous reviewer for their comments on the manuscript. This study is also part of the research project CGL2012-38358 of the Spanish Ministry of Economy and Competitiveness and SGR2014-901 of the Government of Catalonia.

\section{Author details}

1PHES, Institut Català de Paleoecologia Humana i Evolució Social, c/ Marcel lí Domingo s/n (Edifici W3), Campus Sescelades, 43007 Tarragona, Spain. ${ }^{2}$ Area de Prehistoria, Universitat Rovira i Virgili (URV), Avinguda de Catalunya 35, 43002 Tarragona, Spain. ${ }^{3}$ Museum für Naturkunde, Leibniz-Institut für Evolutions- und Biodiversitätsforschung an der Humboldt-Universität zu Berlin, Invalidenstrasse 43, 10115 Berlin, Germany.

Received: 15 September 2014 Accepted: 23 December 2014 Published online: 08 January 2015

\section{References}

Beerli P (1994) Genetic Isolation and Calibration of an Average Protein Clock in Western Palearctic Water Frogs of the Aegean Region. University of Zurich, PhD Dissertation

Beerli P, Hotz H, Tunner HG, Heppich S, Uzzell T (1994) Two new water frog species from the Aegean islands Crete and Karpathos (Amphibia, Salentia,
Ranidae). Notulae Naturae, Academy of Natural Sciences of Philadelphia 470:1-9

Berger $L$ (1966) Biometrical studies on the population of green frogs from the environs of Poznan. Ann Zool 23(11):303-324

Berger $L$ (1968) Morphology of the F1 generation of various crosses within Rana esculenta complex. Acta zoologica cracoviensia 13(13):301-324

Berger $L$ (1990) On the origin of genetic systems in European water frog hybrids. Zoologica Poloniae 35:5-27

Böhme G (1977) Zur Bestimmung quartärer Anuren Europas an Hand von Skelettelementen. Wissenschaftliche Zeitschrift der Humbolt-Universität zu Berlin. Matematisch-Naturwissenschaftliche Reihe 26(3):283-300

Böhme G (1983a) Paläontologische Belege für die Batardierungen bei Raniden (Amphibia, Salientia). Schriftenreihe Geologischen Wissenschaft 19-20:31-37

Böhme G (1983b) Skelettreste von Amphibien (Urodela, Salentia) aus dem fossilen Tierbautensystem von Pisede bei Malchin. Teil 1: Taxonomie und Biostrationomie. Wissenschaftliche Zeitschrift der Humboldt-Universität zu Berlin, Mathematisch-Naturwissenschaftliche Reihe 32:657-680

Böhme G, Günther R (1979) Osteological studies in the European Water Frogs Rana ridibunda, Rana lessonae and Rana "esculenta" (Anura, Ranidae). Mitteilungen aus dem zoologischen Museum in Berlin 55(1):203-215

Dubois A (1991) Nomenclature of parthenogenetic, gynogenetic and "hybridogenetic" vertebrate taxons: new proposals. Alytes 8:61-74

Dubois A, Günther R (1982) Klepton and synklepton: two new evolutionary systematics categories in zoology. Zoologische Jahrbücher/Abteilung für Systematik, Ökologie und Geographie der Tiere 109:290-305

Ebendal T (1979) Distribution, morphology and taxonomy of the Swedish green frogs (Rana esculenta complex). Mitteilungen aus dem Zoologischen Museum in Berlin 55:143-152

Ebendal T, Uzzell T (1982) Ploidy and immunological distance in Swedish water frogs (Rana esculenta complex). Amphibia-Reptilia 3:125-133

Ecker A (1889) The Anatomy of the Frog (Translated by G. Haslam). Clarendon Press, Oxford

Eikhorst R (1987) Der Laich des Teichfrosches Rana esculenta Linnaeus, 1758 in einer reinen Bastardpopulation (Anura: Ranidae). Salamandra 23:122-131

Esteban M, Sanchiz B (1985) Herpetofauna de Erralla. Munibe (Antropología y Arqueología) 37:81-86

Frost DR, Grant T, Faivovich J, Bain RH, Haas A, Haddad CFB, De Sa RO, Channing A, Wilkinson M, Donnellan SC, Raxworthy CJ, Campbell JA, Blotto BL, Moler P, Drewes RC, Nussbaum RA, Lynch JD, Green DM, Wheeler WC (2006) The amphibian tree of life. Bull Am Museum Nat Hist 297:8-370

Gleed-Owen CP (1998) Quaternary Herpetofaunas of the British Isles: Taxonomic Descriptions, Palaeoenvironmental Reconstructions, and Biostratigraphic Implications. Coventry University, PhD Dissertation

Gleed-Owen CP (2000) Subfossil records of Rana cf. lessonae, Rana arvalis and Rana cf. dalmatina from Middle Saxon (c. 600-950 AD) deposits in eastern England: evidence for native status. Amphibia-Reptilia 21(1):57-65

Gubányi A, Korsós Z (1992) Morphological analysis of two Hungarian water frog (Rana lessonae-esculenta) populations. Amphibia-Reptilia 13(3):235-242

Günther R (1975) Zum natürlichen Vorkommen und zur Morphologie triploider Teichfrösche, «Rana esculenta», L., in der DDR (Anura, Ranidae). Mitteilungen aus dem zoologischen Museum in Berlin 51(1):145-158

Günther R (1990) Die Wasserfrösche Europas. A. Ziemsen Verlag, Wittenberg Lutherstadt, pp 72-193

Günther R (1991) Europäische Wasserfrösche (Anura, Ranidae) und biologisches Artkonzept. Mitteilungen aus dem Zoologischen Museum Berlin 67:39-53

Hammer O, Harper DAT, Ryan PD (2001) PAST: Paleontological Statistics. University of Oslo, Oslo

Langton TES, Burton JA (2005) Pool Frog Rana Lessonae in Britain: Past Nativeness Unresolved. On the Verification of Sub-fossil Bone Identification. Reports of the Green Frog Information Programme (GRIP). Herpetofauna Consultants International, Bramfield

Lescure J, de Massary J-C (2012) Atlas des Amphibiens et Reptiles de France. Biotope, Mèze; Muséum national d'Histoire naturelle. Collection Inventaires \& Biodiversité, Paris

Martín C, Sanchiz B (2014) Lisanfos KMS. Version 1.2. Museo Nacional de Ciencias Naturales, MNCN-CSIC, Madrid, Spain, Online reference accessible at http://www.lisanfos.mncn.csic.es/

Mayer M, Hawlitschek O, Zahn A, Glaw F (2013) Composition of twenty green frog populations (Pelophylax) across Bavaria, Germany. Salamandra 49(1):31-44

Monnet J-M, Cherry MI (2002) Sexual size dimorphism in anurans. Proc Royal Soc London B Biol Sci 269(1507):2301-2307 
Plötner J (2005) Die westpaläarktischen Wasserfrösche. Laurenti-Verlag, Bielefeld

Pruvost NBM, Hoffmann A, Reyer H-U (2013) Gamete production patterns, ploidy, and population genetics reveal evolutionary significant units in hybrid water frogs (Pelophylax esculentus). Ecol Evol 3(9):2933-2946

Ratnikov VY (2001a) Pliocene anurans of East-European Platform. Russ J Herpetol 8(3):171-178

Ratnikov VY (2001b) Osteology of Russian toads and frogs for paleontological researches. Acta zoological cracoviensia 44:1-23

Regnier V, Neveu A (1986) Structures spécifiques des peuplements en grenouilles du complexe Rana esculenta de divers milieux de l'Ouest de la France. Acta Oecologica 7(1):3-26

Sanchiz B (1998) Salientia. Handbuch der Paläoherpetologie, part 4. Verlag Dr Friedrich Pfeil, Stuttgart

Sanchiz B, Schleich HH, Esteban M (1993) Water frogs (Ranidae) from the Oligocene of Germany. J Herpetol 27(4):486-489

Shine R (1979) Sexual selection and sexual dimorphism in the Amphibia. Copeia 1979(2):297-306

Sillero N, Campos J, Bonardi A, Corti C, Creemers R, Crochet PA, Isailović JC, Denoël M, Ficetola GF, Gonçalves J, Kuzmin S, Lymberakis P, de Pous P, Rodríguez A, Sindaco R, Speybroeck J, Toxopeus B, Vieites DR, Vences M (2014) Updated distribution and biogeography of amphibians and reptiles of Europe based on a compilation of countrywide mapping studies. Amphibia-Reptilia 35:1-31

Snell C, Tetteh J, Evans IH (2005) Phylogeography of the pool frog (Rana lessonae Camerano) in Europe: evidence for native status in Great Britain and for an unusual postglacial colonization route. Biol J Linn Soc 85:41-51

Thirion J-M, Evrard P (2012) Guide des Reptiles et Amphibiens de France. Editions Belin, Paris

Tunner HG (1974) Die klonale structur eine Wasserfroshpopulation. Zeitschrift für zoologische Systematik und Evolutionforschung 12:309-314

Uzzell T, Berger L (1975) Electrophoretic phenotypes of Rana ridibunda, Rana lessonae, and their hybridogenetic associate, Rana esculenta. Proc Acad Nat Sci Philadelphia 127(2):13-34

Vasilyan D (2009) Lower Vertebrates of the Late Paleogene and Neogene of Armenia. PhD Dissertation. Scientific Center of Zoology and Hydroecology. National Academy of Sciences of the Republic of Armenia, Yerevan

Zahn A (1997) Untersuchungen zum Rana kl. esculenta-lessonae-Komplex in Oberbayern. Salamandra 33:79-88

\section{Submit your manuscript to a SpringerOpen ${ }^{\circ}$ journal and benefit from:}

- Convenient online submission

- Rigorous peer review

- Immediate publication on acceptance

- Open access: articles freely available online

- High visibility within the field

- Retaining the copyright to your article

Submit your next manuscript at $>$ springeropen.com 